\title{
ANALISIS PENINGKATKAN PENDAPATAN PETANI KERAMBA JARING APUNG DENGAN DIVERSIFIKASI SPESIES IKAN BUDIDAYA DI WADUK CIRATA
}

\author{
Abel Gandhy \\ Surya University, Grand Serpong Mall Lt. 1 Unit F8 \& F9, J1. M.H. Thamrin Km 2.7, \\ Kota Tangerang, Indonesia \\ E-mail Korespondensi: abel.gandhy@surya.ac.id \\ Naskah Diterima: Desember 2016; Disetujui: April 2017

\begin{abstract}
The aim of this research is to analyze the impact of diversification of fish cultivation in floating cage at Cirata Reservoir. Indicator of feasibility study based on Net Present Value (NPV), Internal Rate of Return (IRR), Pay Back Period (PP) and Net B/C. The research showed that diversification activities increases NPV Rp 157, 420,576, raise IRR for 38\%, Accelerate the payback period for 3 months and increases the Net B/C from 2.06 to 3,8. Therefore, diversification type of fish cultivation is recomended to apply because will increasing farmer income.
\end{abstract}

Keywords: financial analysis, Internal Rate of Return (IRR), diversification activities JEL Classification: G17, Q00

\begin{abstract}
Abstrak: Tujuan dilakukannya penelitian ini adalah untuk menganalisis pengaruh diversifikasi jenis ikan yang dibudidayakan pada keramba jaring apung di Waduk Cirata. Indikator analisis finansial yang digunakan adalah Net Present Value (NPV), Internal Rate of Return (IRR), Payback Period (PP) dan Net Benefit Cost Ratio (Net B/C). Hasil analisis menunjukkan bahwa kegiatan diversikasi jenis ikan meningkatkan NPV sebesar Rp 157.420.576, meningkatkan Internal Rate of Return (IRR) sebesar 38\%, mempercepat Payback Period selama 3 bulan serta meningkatkan nilai Net B/C dari 2,06 menjadi 3,28. Sehingga kegiatan diversifikasi jenis ikan akan meningkatkan pendapat petani dan layak untuk dilakukan.
\end{abstract}

Kata Kunci : analisis finansial, Internal Rate of Return (IRR), aktifitas diversifikasi Klasifikasi JEL: G17, Q00 


\section{PENDAHULUAN}

Waduk Cirata merupakan salah satu sentra budidaya perikanan air tawar yang terletak di Jawa Barat. Waduk Cirata terbentuk dari adanya genangan air seluas $62 \mathrm{~km}^{2}$ akibat pembangunan waduk yang membendung Sungai Citarum. Genangan waduk tersebut tersebar di tiga Kabupaten, yaitu kabupaten Cianjur, kabupaten Purwakarta, dan kabupaten Bandung. Genangan air terluas terdapat di Kabupaten Cianjur dengan luas 29.603.299 $\mathrm{m}^{2}$ (Aksomo, 2007). Metode budidaya perikanan yang digunakan di waduk Cirata adalah budidaya perikanan Keramba Jaring Apung (KJA). Pada tahun 2012, Jawa Barat mampu memproduksi 195.312 ton ikan yang menggunakan metode jaring apung (BKPM, 2014).

Aktivitas budidaya perikanan sistem keramba jaring apung memiliki tujuan berupa meningkatkan produksi untuk mendapatkan keuntungan maksimum. Pencapaian tujuan produksi didukung oleh kemampuan pembudidaya dalam mengelola input tetap berupa investasi peralatan dan sewa lahan, serta input variabel berupa benih, pakan, perawatan dan lainnya yang merupakan faktor penting untuk dapat mencapai tujuan. Jenis ikan yang umum digunakan pada Keramba Jaring Apung di waduk Cirata adalah ikan Nila dan Ikan Mas. Pola budidaya yang digunakan adalah intensif, dimana ikan ditebar dengan kepadatan yang tinggi serta penggunaan pakan komersial selama proses pembesaran (Ardi, 2013). Dengan pola budidaya intensif, petani dapat memanen ikan dalam waktu yang lebih cepat dengan kualitas yang baik.

Salah satu cara untuk meningkatkan keuntungan petani Keramba Jaring Apung adalah dengan melakukan diversifikasi ikan budidaya yang memiliki nilai ekonomi yang lebih tinggi serta dapat tumbuh dengan baik di lingkungan Waduk Cirata. Jenis ikan yang dapat memenuhi kriteria diatas dan dapat dibudidayakan di Waduk Cirata adalah Ikan hias jenis Koi serta ikan Bawal.

Dalam penelitian ini akan dilihat bagaimana analisis finansial dari praktek diversifikasi ikan yang dibudidayakan ketika diterapkan di Keramba Jaring Apung Waduk Cirata. Analisis finansial merupakan suatu analisis yang membandingkan antara biaya dan manfaat apakah suatu kegiatan bisnis menguntungkan (Husnan, 2003). Analisis finansial yang dilakukan pada penelitian ini adalah Net Present Value (NPV), Internal Rate of Return (IRR), Payback Period (PP), dan Break Even Point (BEP). Pada akhirnya hasil analisis yang didapat diharapkan dapat berguna bagi pengambil keputusan dalam menyusun perencanaan ke depannya.

\section{METODE PENELITIAN}

\section{Lokasi dan Waktu Penelitian}

Penelitian dilakukan di Waduk Cirata, Desa Mande, Kabupaten Cianjur, Jawa Barat pada tanggal 23 Februari 2015 sampai dengan 25 Mei 2015.

\section{Metode Pengumpulan Data}

Metode pengumpulan data dilakukan dengan cara observasi (pengamatan langsung), wawancara, dan studi pustaka. Observasi merupakan pengamatan langsung yang dilakukan ditempat penelitian. Observasi dilakukan di Desa Mande Waduk Cirata, Kabupaten Cianjur, Provinsi Jawa Barat. Wawancara merupakan tanya jawab yang dilakukan oleh pewawancara dan narasumber. Studi pustaka dilakukan dengan mengambil data dari jurnal, penelitian terdahulu, dan dari internet.

\section{Metode Analisis Data}

Pada penelitian ini akan dianalisis pengaruh dari penerapan diversifikasi spesies ikan pada Keramba Jaring Apung. Parameter yang akan dilihat adalah perubahan penerimaan yang akan didapatkan oleh petani 
dengan memperhatikan nilai waktu dari uang yang diperoleh. Sehingga metode analisis data yang digunakan adalah Net Present Value (NPV), Internal Rate of Return (IRR), dan Net Benefit Cost Ratio (Net B/C) dan Payback Period (PP).

\section{Net Present Value (NPV)}

NPV adalah nilai sekarang dari keuntungan bersih (manfaat neto tambahan) yang akan diperoleh pada masa mendatang, merupakan selisih antara nilai sekarang arus manfaat dikurangi dengan nilai sekarang arus biaya (Gittinger, 1986). Jika nilai NPV positif, berarti usaha layak untuk dilakukan, jika bernilai nol berarti tidak untung dan tidak rugi, sedangkan jika bernilai negatif maka usaha tidak layak untuk dilakukan.

Rumus yang digunakan untuk analisis NPV yaitu,

$$
\mathrm{NPV}=\sum \frac{(T R-T C)}{(1+i)^{t}}
$$

Dimana :

$\mathrm{TR}=$ Penerimaan dalam satu periode produksi

$\mathrm{TC}=$ Biaya yang dikeluarkan dalam satu periode priode produksi

$I \quad=$ Tingkat suku bunga

$\mathrm{t} \quad=$ Umur proyek

\section{Internal Rate of return (IRR)}

Internal Rate of Return (IRR) digunakan untuk mencari tingkat bunga yang menyamakan nilai sekarang dari arus kas yang diharapkan dimasa yang akan datang, atau penerimaan kas, dengan mengeluarkan investasi awal (Umar, 2005). IRR merupakan nilai yang menyebabkan nilai NPV proyek sama dengan 0 (Sylvia, 2013).

Rumus yang digunakan yaitu,

$$
\mathrm{IRR}=i_{1}+\frac{N P V_{1}}{N P V_{1}-N P V_{2}} x\left(i_{2}-i_{1}\right)
$$

Keterangan:

Jika IRR = tingkat discount rate maka usaha tidak untung dan tidak rugi.
Jika IRR > tingkat discount rate maka usaha layak untuk dijalankan.

Jika IRR < tingkat discount maka usaha tidak layak untuk dijalankan.

\section{Payback Period (PP)}

Payback period adalah jangka waktu yang diperlukan suatu perusahaan untuk mengembalikan modal investasinya dari cash flow (Gittinger,1986). semakin cepat dana investasi dapat diperoleh kembali, maka semakin kecil resiko yang ditanggung oleh perusahaan. Tujuan PP yaitu untuk menghitung berapa jangka waktu yang dibutuhkan agar modal yang diinvestasikan dapat dikembalikan untuk membiayai usaha. Rumus yang digunakan untuk mencari payback period yaitu:

$$
\text { Payback Period }=\frac{I}{N}
$$

Dimana,

I = biaya investasi

$\mathrm{N}=$ manfaat bersih yang dapat diperoleh setiap tahunnya.

\section{Net Benefit Cost Ratio (Net B/C)}

Net benefit ratio merupakan nilai perbandingan antara present value yang positif dengan present value yang negatif (Soekarwati, 1995).

\section{Net $\mathrm{B} / \mathrm{C}$ Ratio $=\underline{\Sigma P V \text { Net } \text { Benefit yang positif }}$ $\Sigma P V$ Net Benefit yang negatif}

Keterangan:

Jika Net B/C > 1, maka kegiatan usaha layak dilakukan

Jika Net B $\mathrm{C}<1$, maka kegiatan usaha tidak layak dilakukan.

\section{HASIL DAN PEMBAHASAN}

Biaya Investasi budidaya ikan pada Keramba Jaring Apung (KJA)

Investasi adalah biaya awal yang dikeluarkan pada saat awal melakukan suatu 
usaha (Ashari, 2011). Periode proyek yang digunakan adalah 5 Tahun, karena komponen investasi yang digunakan akan habis masa pakainya setelah 5 tahun. Rumah digunakan untuk beristirahat dan saung digunakan untuk tempat berteduh saat melakukan kontrol lapangan serta pemberian pakan ikan. Sinar matahari yang merata sepanjang tahun menyebabkan tenaga surya digunakan untuk sumber penghasil tenaga listrik. Biaya investasi yang dikeluarkan oleh petani ikan Keramba Jaring Apung yang berada di desa Mande propinsi Jawa Barat diperlihatkan pada tabel berikut:

Tabel 1. Biaya investasi Keramba Jaring Apung (KJA) ukuran 7x7 sebanyak 32 unit

\begin{tabular}{lcrr}
\hline \multicolumn{1}{c}{ Komponen } & Kuantitas & Harga Satuan & \multicolumn{1}{c}{ Jumlah } \\
\hline Rumah & 1 & 40.000 .000 & 40.000 .000 \\
\hline Saung & 9 & 3.000 .000 & 27.000 .000 \\
\hline Listrik (genset) & 2 & 2.500 .000 & 5.000 .000 \\
\hline Modul Tenaga Surya & 2 & 3.000 .000 & 6.000 .000 \\
\hline Jaring (kg) & 512 & 100.000 & 51.200 .000 \\
\hline Total Investasi & & & 129.200 .000 \\
\hline
\end{tabular}

Sumber : Data Primer (diolah tahun 2015)

\section{Biaya Tetap}

Biaya tetap adalah komponen biaya produsi yang nilainya tidak dipengaruhi oleh besar kecilnya produksi dan penggunaannya tidak habis dalam satu masa produksi (Ashari, 2011). Biaya tetap merupakan biaya yang tetap dikeluarkan baik saat melakukan produksi ataupun tidak. Total karyawan yang dipekerjakan adalah 4 orang. Sewa lahan per bulan adalah Rp 200.000 yang disetorkan kepada Badan Pengelola
Waduk Cirata (BPWC). Total drum yang digunakan adalah 320 unit, dengan biaya penyusutan drum per bulan Rp 170.000. Perawatan jaring dilakukan untuk menjamin agar jaring tetap berfungsi baik sehingga dapat mencegah ikan yang hilang karena jaring yang rusak. Biaya tetap yang dikeluarkan oleh pemilik KJA adalah seperti yang diperlihatkan pada tabel berikut.

Tabel 2. Biaya Tetap Keramba Jaring Apung (KJA) ukuran 7x7 sebanyak 32 unit

\begin{tabular}{lcrr}
\hline \multicolumn{1}{c}{ Komponen } & Kuantitas & Biaya per Bulan & Jumlah per Tahun \\
\hline Gaji & 4 & 1.500 .000 & 72.000 .000 \\
\hline Sewa Lahan & 1 & 200.000 & 2.400 .000 \\
\hline Penyusutan Drum & 320 & 170.000 & 54.400 .000 \\
\hline Perawatan Jaring & 8 & 50.000 & 4.800 .000 \\
\hline Total Biaya Tetap & & & 133.600 .000 \\
\hline
\end{tabular}

Sumber : Data Primer (diolah tahun 2015)

\section{Biaya Variabel}

Biaya variabel adalah biaya yang nilainya berubah seiring dengan bertambah atau berkurangnya produksi. Setiap periode produksi, bibit ikan mas dan ikan nila yang dibutuhkan adalah $5 \mathrm{~kg}$ per keramba ukuran 7x7. Dalam 1 tahun produksi ikan Mas dilakukan sebanyak 3 kali dan untuk ikan nila sebanyak 2 kali. Total bibit ikan mas dan ikan nila yang dibutuhkan pada 32 keramba untuk setiap periode produksi adalah $160 \mathrm{Kg}$. Ikan Mas hidup dibagian permukaan dari air, sedangkan ikan Nila hidup dibagian dasar dari keramba, sehingga pakan yang tidak terkonsumsi oleh ikan mas akan dimakan oleh ikan Nila. Biaya variabel terbesar adalah untuk Pakan ikan Mas dan Nila yaitu sebesar Rp 387.600 .000 atau lebih dari $95 \%$ total biaya 
variabel. Oleh karena itu keuntungan yang diterima oleh petani sangat dipengaruhi oleh fluktuasi harga pakan. Biaya variabel yang dikeluarkan oleh pembudidaya ikan mas dan ikan nila di KJA Waduk Cirata selama satu tahun ditunjukkan pada tabel berikut:

Tabel 3. Biaya Variabel Keramba Jaring Apung (KJA) ukuran 7x7 sebanyak 32 unit

\begin{tabular}{lccr}
\hline Komponen & Kuantitas & Harga Satuan & \multicolumn{1}{c}{ Jumlah } \\
\hline Bibit Ikan Nila & 320 & 17.000 & 5.440 .000 \\
\hline Bibit Ikan Mas & 480 & 26.500 & 12.720 .000 \\
\hline Pakan Mas Dan Nila & 51.000 & 7.600 & 387.600 .000 \\
\hline Total Biaya Variabel & & & 405.760 .000 \\
\hline
\end{tabular}

Sumber : Data Primer (diolah tahun 2015)

\section{Arus Pendapatan}

Pendapatan adalah jumlah hasil yang diperoleh petani dari penjualan hasil produksi (Mahsaida dkk, 2012). Setiap periode produksi rata-rata Survival Rate yang terjadi pada ikan mas dan nila adalah adalah $85 \%$. Tingkat Food Convertion Ratio ikan mas adalah 0,5 dan Ikan Nila adalah 0,2 dari total pakan yang diberikan. Total Ikan mas yang dihasilkan untuk setiap periode produksi (4 bulan) adalah $250 \mathrm{~kg}$ per keramba, sehingga total ikan Mas yang dihasilkan dalam 1 periode produksi adalah 8 ton. Total ikan nila yang dihasilkan setiap periode produksi (6 bulan) adalah $160 \mathrm{~kg}$ per keramba ukuran $7 \times 7$ meter. Harga ikan yang digunakan adalah harga rata-rata ikan Mas dan Nila pada periode Februari 2014 hingga Februari 2015. Penerimaan yang diperoleh dari ikan mas adalah Rp 456.000 .000 atau $77 \%$ dari total penerimaan petani. Hal ini merupakan fakta bahwa ikan mas merupakan komoditas utama penyumbang penghasilan bagi petani. Total penerimaan yang diperoleh dari ikan Mas adalah Rp 134.400.000. Pendapatan usaha yang diterima oleh petani Keramba Jaring Apung selama 1 tahun ditunjukkan oleh tabel berikut.

Tabel 4. Total Pendapatan Keramba Jaring Apung (KJA) ukuran 7×7 sebanyak 32 unit

\begin{tabular}{lccc}
\hline \multicolumn{1}{c}{ Keterangan } & Kuantitas & Harga Satuan & Jumlah \\
\hline Ikan mas $(\mathrm{kg})$ & 24.000 & 19.000 & 456.000 .000 \\
\hline Ikan nila $(\mathrm{kg})$ & 11.200 & 12.000 & 134.400 .000 \\
\hline Total Penerimaan & & & 590.400 .000
\end{tabular}

Sumber : Data Primer (diolah tahun 2015)

\section{Net Present Value (NPV)}

Tingkat discount rate yang digunakan adalah sebesar $12 \%$ yang didapat dari rata-rata suku bunga pinjaman pada bank di Indonesia.
NPV yang didapatkan selama lima tahun proses produksi dijelaskan pada tabel dibawah ini.

Tabel 5. Net Present Value (NPV) budidaya Ikan Mas dan Nila

\begin{tabular}{cllll}
\hline Tahun Ke- & Penerimaan $(\mathrm{Bt})$ & Biaya $(\mathrm{Ct})$ & Nilai & NPV \\
\hline 0 & & -129.200 .000 & -129.200 .000 & -129.200 .000 \\
\hline 1 & 590.400 .000 & 516.560 .000 & 73.840 .000 & 65.928 .571 \\
\hline 2 & 590.400 .000 & 516.560 .000 & 73.840 .000 & 58.864 .796 \\
\hline 3 & 590.400 .000 & 516.560 .000 & 516.560 .000 & 52.557 .853 \\
\hline 5 & 590.400 .000 & 516.560 .000 & 516.560 .000 & 46.926 .655 \\
\hline Nilai NPV proyek & 590.400 .000 & 516.560 .000 & 516.560 .000 & 41.898 .799 \\
\hline \multicolumn{7}{c}{ Sumber : Data Primer (diolah tahun 2015) } \\
\cline { 1 - 2 } & \multicolumn{1}{l}{} &
\end{tabular}


Net Present value merupakan nilai sekarang dari uang dengan tingkat diskonto tertentu, yang akan diterima oleh pelaku usaha jika menjalakan kegiatan bisnis. Pada tahun ke-0 nilai NPV negatif dikarenakan pelaku usaha harus mengeluarkan uang untuk kegiatan investasi tanpa memperoleh penghasilan. Hal ini dikarenakan kegiatan produksi belum berjalan. Pada tahun ke-1 hingga tahun ke-5 nilai NPV positif dikarenakan kegiatan budidaya telah berjalan sehingga petani memperoleh penerimaan dari penjualan ikan hasil panen. Berdasarkan tabel diatas, NPV yang didapatkan sebesar Rp 136.976.675. Artinya nilai sekarang dari pendapatan selama 5 tahun akan memperoleh keuntungan sebesar
Rp 136.976.675 pada tingkat suku bungan $12 \%$ Nilai positif artinya usaha budidaya Ikan mas dan Nila pada Keramba Jaring Apung layak untuk dilakukan.

\section{Internal Rate of Return}

Internal Rate of Return adalah tingkat discount rate yang menghasilkan NPV proyek usaha budidaya ikan pada Keramba Jaring Apung menjadi sama dengan 0 . IRR didapatkan dengan metode trial and error sampai didapatkan nilai NPV yang negaif. Langkah selanjutnya adalah melakukan interpolasi untuk mendapatkan nilai yang diinginkan. Tabel dibawah ini menjelaskan proses mendapatkan nilai IRR.

Tabel 6. Internal Rate of Return Usaha budidaya Ikan Mas dan Nila

\begin{tabular}{crrr}
\hline Tahun Ke- & \multicolumn{1}{c}{ Nilai } & NPV $(i=40 \%)$ & NPV $(\mathrm{i}=50 \%)$ \\
\hline 0 & -129.200 .000 & -129.200 .000 & -129.200 .000 \\
\hline 1 & 73.840 .000 & 52.742 .857 & 49.226 .667 \\
\hline 2 & 73.840 .000 & 37.673 .469 & 32.817 .778 \\
\hline 3 & 73.840 .000 & 26.909 .621 & 21.878 .519 \\
\hline 4 & 73.840 .000 & 19.221 .158 & 14.585 .679 \\
\hline Nilai NPV proyek & 73.840 .000 & 13.729 .398 & 9.723 .786 \\
\hline
\end{tabular}

Sumber : Data Primer (diolah tahun 2015)

Pada saat discount rate yang dioperasikan adalah $40 \%$, nilai net present value yang dihasilkan adalah $\mathrm{Rp}$ 21.076.504. Sedangkan saat Discount Rate yang dioperasikan adalah $50 \%$, nilai net present value yang dihasilkan adalah Rp -967.572. Kondisi ini mengindikasikan bahwa nilai IRR dari proyek terletak diantara nilai discount rate sebesar $40 \%$ dan 50\%. Dengan metode interpolasi maka akan didapatkan nilai discount rate yang menyebabkan nilai Net Present Value proyek menjadi 0. Nilai Internal Rate Return adalah sebesar $49 \%$. Jadi, hal ini menunjukkan usaha budidaya Ikan Mas dan Nila pada Keramba Jaring Apung layak untuk dijalankan, karena IRR (49\%) lebih besar dari tingkat cost of capital (12\%), yaitu tingkat suku bunga kredit pada perbankan di Indonesia.

\section{Payback Period}

Payback Period digunakan untuk mengukur seberapa cepat investasi akan kembali. Nilai Pay Back Period yang terjadi dari kegiatan usaha budidaya Ikan Mas dan Nila pada Keramba Jaring Apung adalah 1 Tahun 5 Bulan. Artinya, dalam kurun waktu tersebut total investasi yang dikeluarkan oleh petani sudah kembali.

\section{Net Benefit Cost Ratio (Net B/C)}

Net B/C adalah perbandingan nilai present value yang bernilai negatif dengan present value yang bernilai negatif. Nilai Net B/C dari budidaya ikan Mas dan Nila pada keramba jaring apung di Waduk Cirata adalah 2,06. Nilai Net B/C lebih besar dari 1 berarti kegiatan usaha layak untuk dilakukan. 
Usaha Budidaya Dengan Diversifikasi Jenis Ikan

Diversifikasi merupakan kegiatan usaha budidaya untuk menambah jenis ikan yang dipelihara dengan tujuan untuk meningkatkan pendapatan petani keramba jaring apung. Variasi ikan yang dibudidayakan harus disesuaikan dengan karakteristik perairan waduk Cirata, dengan demikian pertumbuhan ikan dapat berlangsung secara optimal serta tingkat mortalitas ikan menjadi rendah. Tambahan ikan yang dibudidayakan terdiri dari ikan hias jenis Koi dan ikan Bawal. Alasan lain pemilihan jenis ikan-ikan tersebut adalah karena tersedianya pasar yang akan menampung ikan hasil panen.

Skema budidaya ikan dalam keramba jaring apung terdiri dari 28 keramba ukuran 7 x 7 meter berisi Ikan Mas dan Ikan Nila, 2 Keramba berisi ikan bawal dan 2 keramba berisi ikan hias jenis Koi. Total keramba yang digunakan adalah 32 unit. Biaya investasi dan biaya tetap yang digunakan saat dilakukan diversifikasi jenis ikan nilainya sama dengan budidaya yang hanya membudidayakan ikan Mas dan ikan Nila. Total Biaya investasi yang dikeluarkan oleh petani adalah Rp 129.200.000 dan Total biaya tetap per tahun adalah $\mathrm{Rp}$ 133.600.000.

\section{Biaya Variabel}

Dengan adanya diversifikasi jenis ikan, maka terdapat tambahan biaya untuk pembelian bibit ikan hias jenis Koi dan ikan Bawal. Disisi lain jumlah bibit ikan Mas dan Nila akan berkurang, karena alokasi keramba berkurang untuk kedua jenis ikan tersebut. Keadaan yang sama juga terjadi untuk komponen pakan ikan. Biaya variabel yang dikeluarkan petani selama satu tahun pada proses budidaya keramba jaring apung disajikan dalam tabel 7.

Tabel 7. Biaya Variabel Budidaya Keramba Jaring Apung Dengan Diversifikasi

\begin{tabular}{llll}
\hline \multicolumn{1}{c}{ Komponen } & \multicolumn{1}{c}{ Kuantitas } & \multicolumn{1}{c}{ Harga Satuan } & \multicolumn{1}{c}{ Jumlah } \\
\hline Bibit Ikan Nila & 150 & 17.000 & 4.760 .000 \\
\hline Bibit Ikan Hias & 15 & 100.000 & 6.000 .000 \\
\hline Bibit Ikan Mas & 150 & 26.500 & 11.130 .000 \\
\hline Bibit Ikan Bawal & 30 & 50.000 & 600.000 \\
\hline Pakan Mas & 15.000 & 7.600 & 342.000 .000 \\
\hline Pakan Hias & 1.500 & 10.000 & 45.000 .000 \\
\hline Pakan Bawal & 1.700 & 7.600 & 38.760 .000 \\
\hline Total Biaya Variabel & & & 448.250 .000
\end{tabular}

Sumber : Data Primer (diolah tahun 2015)

\section{Arus Pendapatan}

Tingkat Food convertion Ratio (FCR) ikan bawal adalah 0,8 . Ikan hias jenis Koi dijual per ekor, dengan harga jual Rp 20.000/ekor. Panen ikan Koi dan Bawal dilakukan setiap 3 bulan sekali. Pendapatan usaha setelah dilakukannya diversifikasi jenis ikan yang dibudidayakan ditunjukkan oleh tabel 8 .

Tabel 8. Pendapatan Dengan Diversifikasi Jenis Ikan yang dibudidayakan

\begin{tabular}{lccc}
\hline \multicolumn{1}{c}{ Komponen } & Kuantitas & Harga Satuan & Jumlah \\
\hline Ikan mas (kg) & 21.000 & 18.500 & 399.000 .000 \\
\hline Ikan nila (kg) & 11.200 & 12.000 & 134.400 .000 \\
\hline Ikan Hias (ekor) & 6.000 & 20.000 & 120.000 .000 \\
\hline Ikan Bawal (Kg) & 2.400 & 12.500 & 30.000 .000 \\
\hline \multicolumn{1}{c}{ Total Penerimaan } & & & 683.400 .000 \\
\hline
\end{tabular}

Sumber : Data Primer (diolah tahun 2015) 
Kriteria Finansial Usaha Budidaya Dengan Diversifikasi Jenis Ikan

Kriteria finansial yang dihasilkan dengan melakukan diversifikasi jenis ikan yang dibudidayakan dalam keramba jaring apung dapat dilihat pada tabel 9 .

Tabel 9. Pendapatan Dengan Diversifikasi Jenis Ikan yang dibudidayakan

\begin{tabular}{cc}
\hline Kriteria Finansial & Nilai \\
\hline NPV & 294.397 .251 \\
\hline IRR & $87 \%$ \\
\hline Payback Period & 1 Tahun 2 Bulan \\
\hline Net B/C & 3,28 \\
\hline
\end{tabular}

Sumber: Data Primer (diolah tahun 2015)

Nilai Net Present Value (NPV) usaha budidaya dengan diversifikasi jenis ikan adalah Rp 294.397.251. Nilai NPV meningkat sebesar Rp 157.420 .576 dibandingkan budidaya ikan Mas dan Nila pada tempat yang sama. Fakta tersebut menunjukkan kegiatan usaha budidaya dengan diversifikasi jenis ikan memberikan peningkatan pendapatan bagi petani.

Kondisi yang sama terjadi pada Internal Rate of Return (IRR). Dengan adanya diversifikasi jenis ikan, IRR meningkat dari 49\% menjadi $87 \%$. Terjadi peningkatan sebanyak $38 \%$ dari Internal Rate of Return.

Petani juga akan memperoleh waktu yang lebih cepat untuk pengembalian investasi yang dilakukan pada usaha budidaya ikan dengan keramba jaring apung. Dengan dilakukannya diversifikasi jenis ikan, Payback Period usaha adalah 1 Tahun 2 Bulan. Nilai tersebut 3 bulan lebih cepat jika dibandingkan budidaya yang dilakukan hanya ikan Mas dan Nila saja.

Indikator Net Benefit Cost Ratio (Net B/C) juga menunjukkan hasil yang lebih baik. Jika usaha budidaya hanya menggunakan ikan Mas dan Nila saja nilainya 2,06, maka dengan adanya diversifikasi nilainya menjadi 3,28. Nilai yang lebih besar artinya usaha budidaya semakin layak untuk dilakukan.

\section{SIMPULAN}

Usaha budidaya ikan pada Keramba Jaring Apung yang dilakukan di Waduk Cirata pada umumnya membudidayakan ikan Mas dan Nila. Indikator analisis Finansial Usaha budidaya yang dilakukan terdiri dari Net Present Value (NPV) bernilai Rp 136.976.675, Internal Rate of Return (IRR) adalah 49\%, Payback Period (PP) adalah 1 Tahun 5 Bulan dan Net B/C adalah 2,06. Keseluruhan indikator analisis Finansial menyatakan usaha budidaya ikan pada Keramba Jaring Apung layak untuk dilakukan.

Diversifikasi jenis ikan yang dibudidayakan menggunakan ikan hias jenis Koi dan ikan bawal. Pertimbangan penggunaan kedua jenis ikan tersebut karena cocok dengan karakteristik perairan Waduk Cirata dan memiliki nilai ekonomis yang tinggi. Indikator analisis finansial yang dihasilkan adalah peningkatan Net Present Value (NPV) sebesar Rp 157.420.576, peningkatan Internal Rate of Return (IRR) sebesar 38\%, mempercepat Payback Period selama 3 bulan serta meningkatkan nilai Net B/C dari 2,06 menjadi 3,28. Indikatorindikator tersebut menunjukkan bahwa kegiatan budidaya dengan diversifikasi jenis ikan direkomendasikan untuk petani, karena akan meningkatkan pendapatan petani. Dengan demikian petani direkomendasikan untuk menerapkan diversifikasi budidaya jenis ikan karena akan meningkatkan pendapatan yang diperoleh dengan luas lahan budidaya yang sama.

Rekomendasi untuk penelitian selanjutnya dimasa yang akan datang adalah perlunya 
dilakukan kajian pengguaan spesies ikan lain untuk diversifikasi budidaya jenis ikan. Syarat yang harus dipenuhi adalah ikan yang memiliki nilai ekonomis tinggi dan cocok dibudidayakan dengan lingkungan perairan waduk cirata. Selain itu, perlu juga dilakukan kajian analisis sensitivitas untuk mengetahui pengaruh perubahan parameter seperti harga ikan dan harga pakan terhadap parameter analisis finansial.

\section{DAFTAR PUSTAKA}

Aksomo.R. 2007. Nilai Ekonomi Pemanfaatan Waduk Cirata untuk Perikanan dan Wisata Tirta di Kabupaten Cianjur, Jawa Barat. Manajemen Bisnis dan Ekonomi Perikanan-Kelautan. Fakultas Perikanan dan Kelautan. Institut Pertanian Bogor.

Ardi, Idil. 2013. Budidaya Ikan Sistem Keramba Jaring Apung Guna menjaga Keberlanjutan Lingkungan Perairan Waduk Cirata. Pusat Penelitian dan Pengembangan Perikanan Budidaya. Jakarta.

BKPM. (2014). Potensi Budidaya Jaring Apung di Jawa Barat. Diperoleh dari http://regionalinvestment.bkpm.go.id/ newsipid/commodityarea.php?ia $=32 \& \mathrm{i}$ c=1565._Diunduh tanggal 27 Januari 2015 pukul 15.20.

Gittinger, J. Price. 1986. Economic Analysis of Agricultural Projects. $2^{\text {nd }}$ Edition. Baltimore: John Hopkins University Press.

Husnan, Suad. 2003, Manajemen Keuangan Teori dan Penerapan. Edisi keempat, BPFE, Yogyakarta.

Soekarwati. 1995. Analisis Usaha Tani. Jakarta : UI Press.

Sylvia, Rika. 2013. Analisis Investasi Pendirian Home Industry Keripik Singkong di Desa Gunung Ulin Kabupaten Kotabaru Kalimantan Selatan. Jurnal Ekonomi Manajemen Vol. 7 No. 1 (2013).
Umar, Husein. 2001. Study Kelayakan Bisnis. Edisi 3 Revisi, Gramedia Pustaka Utama, Jakarta. 